\title{
Marshall parameters for quality control of hot mix asphalt after pavement construction
}

\author{
Parámetros Marshall para el control de calidad de mezclas asfálticas en caliente después de la \\ construcción del pavimento
}

Jaime Bojorque Iñeguez (Main and contact author)

Civil Engineering Department, Faculty of Civil Engineering, University of Cuenca

Av. 12 de Abril s/n, Cuenca (Ecuador)

jaime.bojorque@ucuenca.edu.ec

\section{Cristian Flores}

Independent Consulting Engineer

Calle Guayas 6-143, Cuenca (Ecuador)

cristian_flores@consulproy.com

\section{Mario Vásquez}

Independent Consulting Engineer

Calle Larga 6-13, Cuenca (Ecuador)

mvasquez@consultoracav.com.ec

Manuscript Code: 1159

Date of Acceptance/Reception: 20.04.2019/16.08.2018

DOI: $10.7764 / R D L C .18 .1 .178$

\begin{abstract}
Highways have been and are built using Hot Mix Asphalt (HMA) as surface layer. The most common HMA design procedure is the Marshall Method, a method also used for quality control (QC) at the time of road construction. Due to several factors, sometimes it is not possible to sample the surface layer when constructed. When this occurs, QC is performed after construction by analyzing cores. Current regulations, however, fail having clear procedures regarding the collection and analysis of pavement cores after the complete placement of the asphalt mixture. For this reason, this study proposes a comparative analysis of Marshall parameters, mixture densities, and aggregates gradation obtained from specimens obtained during construction, versus cores samples extracted 30 and 60 days later. The research revealed that all the parameters measured on core samples, except flow, could be used to approve asphalt paving works after its construction.
\end{abstract}

Keywords: Hot mix asphalt, quality control, pavement construction, Marshall Test, stability and flow.

Resumen

Las carreteras han sido y son construidas empleando Mezclas Asfálticas en Caliente (HMA) como capa de superficie. El procedimiento más común de diseño de HMA es el Método Marshall, método que también se usa para el control de calidad (QC) en el momento de la construcción de la vía. Debido a varios factores, en ocasiones no es posible tomar muestras de la capa superficial en el momento de la construcción. Cuando esto ocurre, el QC se lo realiza después de la construcción mediante la extracción de núcleos. Las especificaciones actuales, sin embargo, no indican procedimientos claros con respecto a la recolección y análisis de los núcleos del pavimento después de la colocación de la mezcla asfáltica. Por esta razón, este estudio propone un análisis comparativo de los parámetros Marshall, densidades de mezcla y granulometría de los agregados, obtenidos de muestras extraídas durante la construcción y de núcleos extraídos 30 y 60 días después. La investigación reveló que todos los parámetros medidos en núcleos, excepto el flujo, podrían ser utilizados para aprobar los trabajos de pavimentación asfáltica después de su construcción.

Palabras clave: Mezcla asfáltica en caliente, control de calidad, construcción del pavimento, Ensayo Marshall, estabilidad y flujo.

Introduction

In Ecuador, as in many countries, primary roads are constructed with flexible pavement using Hot Mix Asphalt (HMA). HMA is a combination of coarse and fine aggregates, bitumen and air, mixed and placed in hot. The extensive use of these mixtures is due to their good performance under traffic loads, environmental factors, and initial construction costs. Hot mixes, designed as surface layers, should provide minimum characteristics such as friction, smoothness, noise control, rutting resistance and sufficient drainage (USDOT, 2001). The Marshall Method continues to be in Ecuador and other countries the design and control guide for HMA. The objective of the HMA design method is to correlate laboratory results with actual field performance. According to Roberts, Kandhal, Brown, Lee, \& Kennedy (1996), HMA was developed with the following objectives in mind: i) rutting resistance, (ii) fatigue cracking resistance; (iii) low temperature cracking resistance; (iv) durability; (v) moisture attack resistance; (vi) skid resistance; and vii) workability. 
These criteria have to be taken into consideration during laboratory mix design. Other design methods, like Superpave, are not yet widely used due to its higher demand in the characterization of materials involving additional investment in time and money.

It is the contractor's responsibility to ensure quality in the production and placement of the asphalt mix. Contractors, therefore, must ensure that materials and the placing procedure are adequate and meet the project Quality Assurance (QA) and Quality Control (QC) specifications. QA is defined as all those planned and systematic actions necessary to provide confidence that a product will perform satisfactorily in service. While, QC is defined as those QA actions and considerations necessary to assess and adjust production and construction processes so as to control the level of quality being produced in the end product (TRB, 2005). To guarantee QA and QC, independent inspection is enforced along with Contractor's control (TRB, 2000). However, due to different operational and administrative drawbacks or measurement errors, delays in inspection occur. Additionally, final road construction payment is completed after months. In many of these cases, core extractions for QC are taken months after construction. The characteristics of core samples are for control compared with laboratory specifications, considering among other parameters the mixture density, stability and flow, air voids (VA), voids in mineral aggregate (VMA), percentage of voids filled with asphalt (VFA), content of asphalt bitumen, filler / bitumen ratio, and mixture gradation (MTOP, 2002). If all required specifications are met, the inspector accepts the asphalt pavement, otherwise the respective corrections will be requested at the contractor's cost.

However, when core samples are extracted after road completion, some parameters may differ from what is required, resulting in discussions and possible lawsuits between those involved. Complaints thereby could be related to the gradation, stability, flow, mixture density and/or percentage of voids of the asphalt mix. In the absence of quality standards of HMA over time, as indicated by Hu, Jiang, \& Pan (2017), it is necessary to have an approximation of HMA performance of cores extracted at different times after placement. The available standards are valid for hot mix asphalt before and during pavement, but little is known whether these standards are still useable for the quality checking of asphalt core samples time after road construction. Literature on performance assessment of asphalt over time is very scary and limited, and seemingly only available for the Hamburg Wheel Tracking Test (HWTT). In the study carried out by Walubita, Faruk, Zhang, Hu, \& Lee (2016), using the HWTT it was found that the rutting resistance of hot mixes increases with time, indicating that differences in test times can lead to misinterpretations in the rutting prediction. Additionally, from the study carried out by Hu et al. (2017) for different types of asphalt mixtures, it was observed that laboratory samples tested at different times have significant variations, and that differences depend on particular procedures and objectives of each test. These authors proposed that aging by oxidation and evaporation of the volatile organic compounds of asphalt can be the cause of the stiffening, likely the cause of variations in tests results over time.

Aging of asphalt mixtures is due to mechanical, physical, chemical and rheological processes (Fernández Gómez, Rondón Quintana, \& Reyes Lizcano, 2013). To evaluate the behavior of mixtures over time, different techniques to accelerate the aging process were proposed (Airey, 2003). For example, extended heating procedures, oxidation tests, ultraviolet and infrared treatments and steric hardening. It was observed that the aging process of asphalt mixtures occurs in two periods. Short-term aging is mainly due to the volatilization of bitumen within the asphalt mixture during processing and construction, while long-term aging is the result of oxidation and steric hardening. Airey (2003) suggested that considering asphalt mixtures are constructed correctly, the main factors that affect the durability of bituminous paving mixtures are age hardening and moisture damage. Aging of bitumen occurs as an increase in its viscosity and moisture, while damage is presented as a loss of cohesion and adhesion between bitumen and the aggregate interface. Rondón Quintana \& Reyes Lizcano (2012) analyzed with time the variation of resilient modulus, permanent deformation and fatigue resistance of asphalt mixtures in Colombia. For mixes made with asphalt bitumen CA 60-70 an increase in stiffness is generally produced by aging of the bitumen, resulting in an increase of the rutting and fatigue cracking potential. Factors that cause inappropriate asphalt mixtures include, as stated by Ogundipe (2016), texture and gradation of the aggregates, VA, VMA, VFA, type of bituminous binder, and mixing temperature. These parameters are related to stability and flow values derived with the Marshall test.

For the correct assessment of the quality of asphalt mixtures after construction, inspectors should be knowledgeable of the effect of aging. Since knowledge of the change with time of the Marshall parameters and mixture densities of pavement after construction is limited, the overall purpose of this study is to contribute to the understanding of the change over time of the HMA properties. Comprehension of the time change in these parameters will enable inspectors to conduct the quality control of asphalt mixtures even after a period of time on the basis of the analysis of core samples. 


\section{Marshall Test}

Marshall stability and flow of asphalt mixtures, along with field mixture density, VA, VMA and/or VFA, are used for bituminous mix design in laboratory and in-situ control. In addition, the Marshall parameters are very useful for controlling the plant production process of asphalt mixtures (ASTM D6927). The Marshall Test is performed on cylindrical samples of 4 in $(102 \mathrm{~mm})$ in diameter and thickness of $2.5 \pm 0.10$ in $(63.5 \pm 2.5 \mathrm{~mm})$. The specimens are exposed to a water bath with a temperature of $60 \pm 1^{\circ} \mathrm{C}$. The load is applied by means of a gage-equipped hydraulic jack at a rate of $2.00 \pm 0.15 \mathrm{in} / \mathrm{min}(5.08 \pm 0.38 \mathrm{~cm} / \mathrm{min})$ until break point is reached or the load begins to decrease. Commonly, the maximum load reached is defined as stability, while the vertical deformation at maximum load is recorded as flow. Although the Marshall design has its limitations, the method is recognized as an appropriate approach providing crucial information guaranteeing the production of high quality HMA's.

Stability of the mixture reflects the internal friction and cohesion whereby cohesion is a measure of the bitumen binding strength, and internal friction a benchmark of the interlocking and friction resistance of aggregates. On the other hand, flow is a measure of the sample deformation. High flow values generally indicate a plastic mixture that will undergo permanent deformation under traffic, whereas low values may indicate a mixture with larger than normal voids and insufficient asphalt to ensure durability and premature cracking could be experienced due to the fragility of the mixture (Roberts et al., 1996).

\section{Materials and mix design procedure}

The research was carried out on the "Gualaceo - Plan de Milagro road" (Ecuador), an artery that connects the southern region of the Ecuadorian highlands with the eastern region. The aggregates were obtained from two locations, the 3/4 in $(19.0 \mathrm{~mm})$ and $3 / 8$ in $(9.50 \mathrm{~mm})$ sieve fractions from the "Cerro Tamuga" and the fine part, corresponding to sands, from the "Bulubulu" river banks, sector of "Cochancay". The coarse material was obtained by $100 \%$ crushing process. The asphalt bitumen was the AC-20, from Esmeraldas-Ecuador refinery. The technical standards that were used for the characterization of aggregates, asphalt bitumen and asphalt mix correspond to those described in the document "General Specifications for the Construction of Roads and Bridges", MOP-001-F-2002" (MTOP, 2002). These standards are used as well for acceptance of HMA works.

In this project, all bitumen parameters met the specifications. Asphalt bitumen has to have a 60 to $70 \mathrm{~mm} / 100$ penetration. Additionally, the bitumen viscosity - temperature curve was generated in order to determine the optimal temperatures, for both, mixing and placing. According to the standard, the bitumen content must be $\pm 0.3 \%$ from the mix design optimum value. Furthermore, it was verified that the aggregates meet the requirements for asphalt covering aggregates in the presence of water, sand equivalence, deleterious, sulfates resistance, elongated and flattened particles, fractured faces, plasticity index and abrasion by the Los Angeles Machine. The properties of asphalt bitumen used in the study are listed in Table 1, and the physical properties of aggregates are shown in Table 2. The limits are based on the current regulations of MTOP.

Table 1. Properties of asphalt bitumen (AC-20). Source: Self-elaboration.

\begin{tabular}{|c|c|c|c|}
\hline Test & Specification & MTOP limits & Value \\
\hline Penetration at $25 \circ \mathrm{C}(0.1 \mathrm{~mm})$ & ASTM D5 & $60-70$ & 69 \\
\hline Softening point $(\stackrel{\circ}{\circ})$ & ASTM D36 & $48-57$ & 50.2 \\
\hline Flash point $(\stackrel{\circ}{ } \mathrm{C})$ & ASTM D92 & $232(\min )$ & 280 \\
\hline Density of binder & ASTM D70 & - & 1.014 \\
\hline Viscosity at $60 \circ \mathrm{C}(\stackrel{\circ}{\mathrm{C}})$ & ASTM D4402 & 240 (max) & 240 \\
\hline Kinematic viscosity at $135^{\circ} \mathrm{C}(\mathrm{o} \mathrm{C})$ & ASTM D2170 & 300 (min) & 381.2 \\
\hline Mass loss (\%) & ASTM D1754 & 1 (max) & 0.5 \\
\hline Ductility at $25 \circ \mathrm{C}(\mathrm{cm})$ & ASTM D113 & 50 (min) & 52 \\
\hline
\end{tabular}


Table 2. Physical properties of aggregates. Source: Self-elaboration.

\begin{tabular}{llcc}
\hline \multicolumn{4}{c}{ Table 2. Physical properties of aggregates. Source: Self-elaboration. } \\
\hline Test & Specification & MTOP limits & Value \\
\hline Stripping of bitumen-aggregate (\%) & ASTM D1664 & $<5$ & 3 \\
Sand equivalent value (\%) & ASTM D2419 & $<50$ & 49 \\
Los Angeles abrasion loss (\%) & ASTM C131 & $<40$ & 24.5 \\
Clay lumps and friable particles (\%) & ASTM C142 & $<1$ & 0.27 \\
Soundness by sodium sulfate (\%) & ASTM C88 & $<12$ & 3.9 \\
Flat and elongated particles (\%) & ASTM D4791 & $<10$ & 0.2 \\
Fractured particles (\%) & ASTM D5821 & $>85$ & 99 \\
\hline
\end{tabular}

The aggregate grading curves, constructed according to MTOP specifications, are depicted in Figure 1 . The sieves' opening range related with sieve percentage passing is indicated, as well as the working formula and mix design grading, considering a $1 / 2$ in $(12.5 \mathrm{~mm})$ maximum aggregate size. The working formula is obtained from the design curve plus/minus the tolerance values that depend on sieve size. The working formula is used for the mix production to have the aggregate within the grading range.

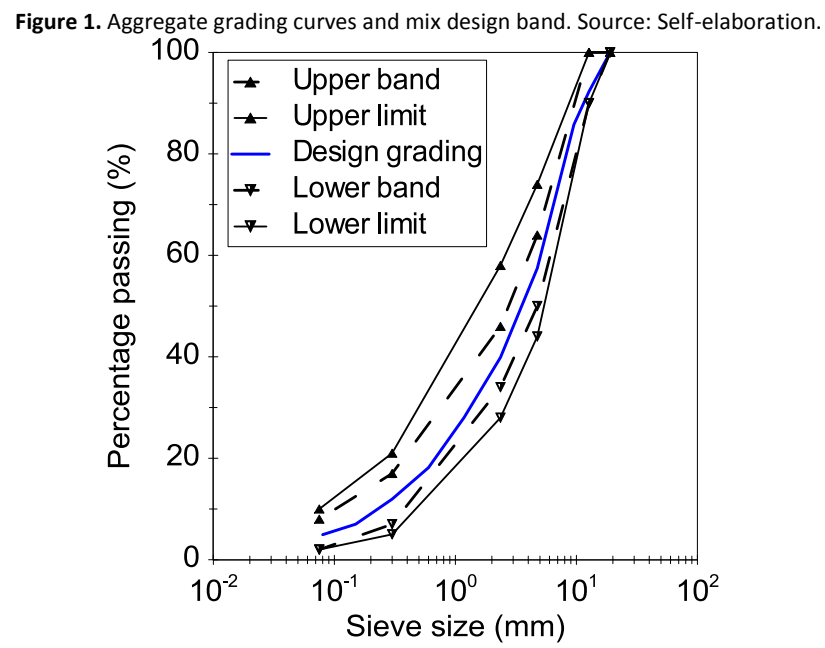

Materials' specifications for HMA depend on road traffic intensity. The "Gualaceo - Plan de Milagro road" is classified has a -heavy traffic- road. Table 3 summarizes the Marshall technical specifications of asphalt mixtures for heavy traffic (MTOP, 2002).

\begin{tabular}{lcc}
\multicolumn{3}{l}{ Table 3. HMA requirements for heavy traffic (adapted from MTOP, 2002). } \\
\hline Marshall Test & Minimum & Maximum \\
\hline \# blows & & 75 \\
Stability (lb) & 1800 & -- \\
Flow (in/100) & 8 & 14 \\
VA (\%) & 3 & 5 \\
VMA (\%) & 14 & -- \\
\hline
\end{tabular}

The design HMA was based on the results of the optimum asphalt content. Samples (tree for each percentage) were prepared at 0.5 percent by weight of mix increments. Six percentages of asphalt $(5.0,5.5,6.0,6.5,7.0$ and 7.5$)$ were used to determine the stability, flow, density, VMA, VFA and VA for each specimen. The optimum asphalt content was the asphalt content corresponding to an air voids ratio of $4 \%$ (median specification air void content). Samples were prepared with the optimum asphalt content to compare each of the parameters values against the specifications. For this percentage, optimum bitumen value was $6.1 \%$, bulk density 2.363 , RICE density 2.469 , stability $2730 \mathrm{lb}$, flow 12 in/100, VMA $14.6 \%$ and VFA 74\%, values that fulfilled the MTOP-2002 regulations.

Considering that QC is fundamental for ensuring good pavement performance, the control of the quality was conducted in compliance with current regulations. Two important parameters, additional to those described above, were defined in the field; these are the temperature (measured with a calibrated asphalt thermometer) and the degree of mix compaction (evaluated with a nuclear densometer). Compacted mix density must be equal to or greater than $97 \%$ of 
the laboratory maximum density, and the compaction temperature should be within 85 to 163 으 $\mathrm{C}$ to avoid horizontal displacement of the mixture under rollers. Additionally, the finished mixture thickness should not vary by more than 0.24 in $(6 \mathrm{~mm})$ from the 2 in design value.

\section{Samples and cores}

For the preparation of in situ samples material was taken at the time of asphalt placement. Nine sampling sectors were selected, and 3 samples were prepared for each site. For the mix compaction, 75 hammer blows per side were used as specified (Table 3). After 30 and 60 days of placement of the asphalt mixture, 3 cores were extracted in each of the defined sectors in order to investigate the time effect on mixture characteristic. A total of 81 specimens were obtained for analysis. In the samples and cores were the Marshall parameters, densities, asphalt extraction and gradation measured. In addition, the degree of mix field compaction was determined using a nuclear densometer.

According to Decker (2017) are the three most important parameters to consider in obtaining adequate pavement density roller operation, mix design and asphalt bitumen content. To determine the appropriate degree of compaction, a test section was made using the available machinery that included an 8-ton tandem roller and a pneumatic roller. From this section, and based on the constructor's experience, the requirement was defined to pass twice the tandem roller, one round pass and one round back, and 24 passes of the pneumatic roller, 12 forwards and 12 backwards.

Results and discussion

\section{Aggregates gradation}

One of the most relevant factors in performance-based design of asphalt mixtures is the gradation of the aggregates. Valdés Vidal, Calabi-Floody, and Sánchez-Alonso (2015) identified that the role of aggregates in the performance and durability of an asphalt mixture is critical. Therefore, in this study, attention was given to the gradation control points

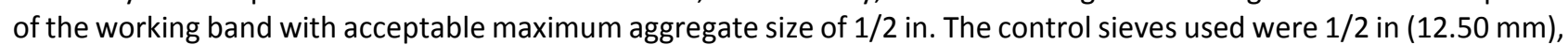
$\# 4(4.75 \mathrm{~mm}), \# 8(2.36 \mathrm{~mm}), \# 50(0.30 \mathrm{~mm})$ and \#200 (0.075 mm), with lower and upper limits (percentage passing) of 90-100, 51-65, 34-46, 7-17, and 2-8, respectively (Figure 1).

Figure 2 shows the results of the grading analysis of samples and cores. Results for all control sieves fall within the working range. For the case of the sieve $1 / 2$ in $(12.50 \mathrm{~mm}$ ) (Figure $2 \mathrm{a}$ ) is the minimum value for samples $90.30 \%$; although close to the lower limit the aggregate gradation complies with the regulations. In all core samples is the aggregate gradation above this value, with the lowest value being $91.30 \%$ satisfying the $90 \%$ threshold. The maximum value of both samples and cores is $97.76 \%$, lower than the requested $100 \%$. For sieve \#4 (4.75 mm) (Figure $2 \mathrm{~b}$ ) is the minimum percentage $53.69 \%$, higher than $51 \%$ of the working band. Its maximum value is $64.07 \%$, which is close to the upper limit of $65 \%$ but within the specification. For sieve $\# 8(2.36 \mathrm{~mm})$ are all percentages within the specified range of $34-46 \%$, with a minimum value of $35.80 \%$ and a maximum of $44.32 \%$. For $\# 50$ sieve $(0.30 \mathrm{~mm})$ (Figure $2 \mathrm{c}$ ) is the minimum value $9.62 \%$ and the maximum value $15.51 \%$, with lower and upper limits of 7 and $17 \%$, respectively. In sieve \#200 $(0.075 \mathrm{~mm})$ (Figure $2 \mathrm{~d}$ ) are the limits $(2-8 \%)$ for samples and cores met, corresponding to a minimum of $3.01 \%$ and a maximum of $5.30 \%$.

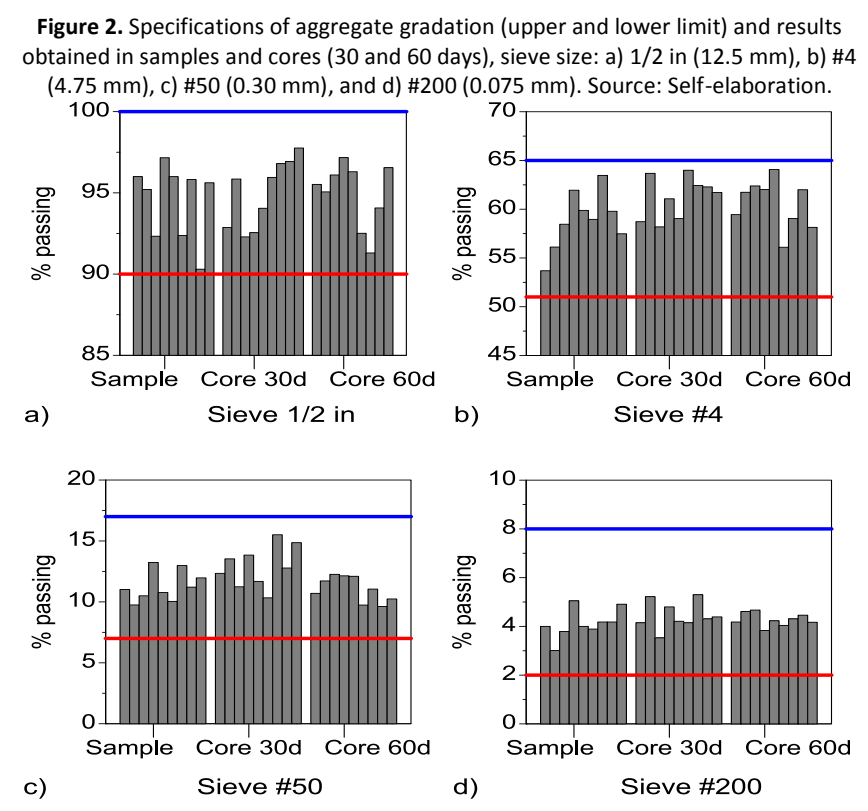


Extraction of the bitumen for the verification of the aggregates gradation revealed that the bitumen percentages in all the samples were within the acceptable range of $6.10 \pm 0.3 \%$, between 5.80 and $6.29 \%$.

\section{Degree of mix compaction}

The degree of mix compaction must be equal to or greater than $97 \%$ of the maximum density established in the laboratory. Densities were evaluated at the time of mixture placing and then at 30 and 60 days after. An average of $100.3 \%$ with respect to the laboratory density was obtained. Figure 3 shows the mix compaction percentages at different sites, with a minimum compaction value of $98 \%$ and a maximum of $102 \%$, indicating that all field density measurements were acceptable.

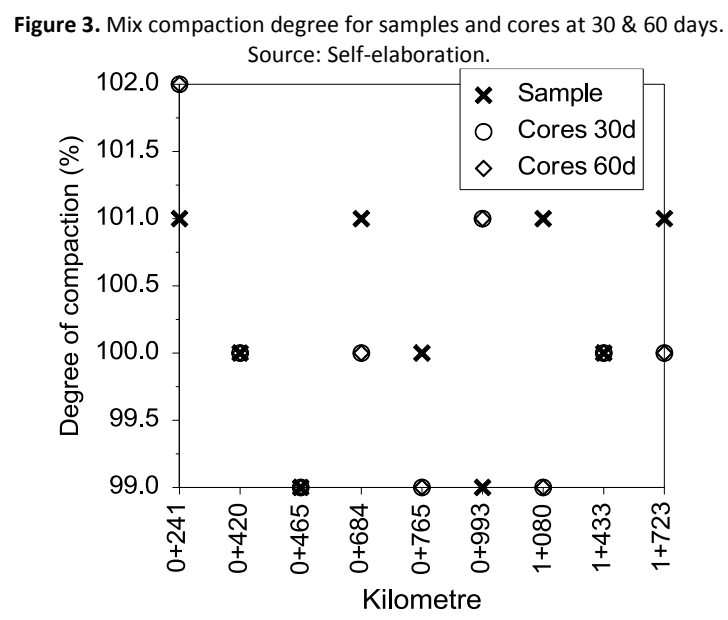

\section{Marshall parameters}

Figure 4 shows the box and whisker plots for densities, VA and VMA for samples and cores. The box plots present the three quartiles (lower, middle and upper) and the minimum and maximum value, facilitating the visualization and analysis of the results.

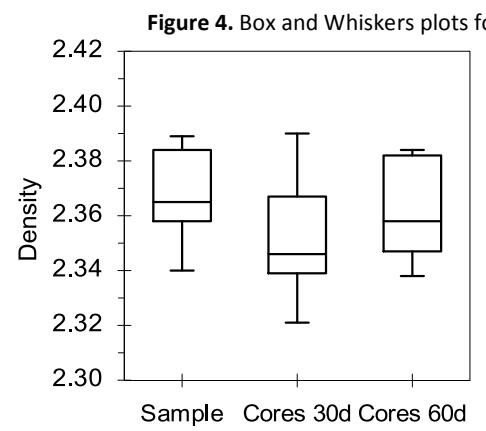

a)

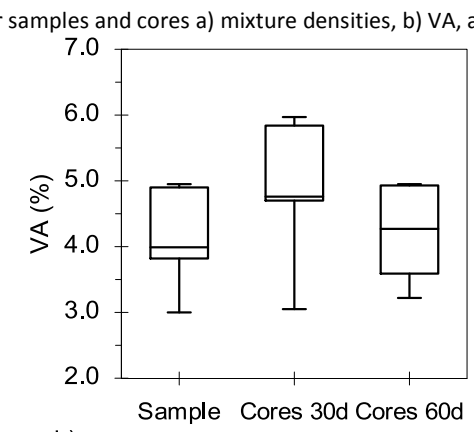

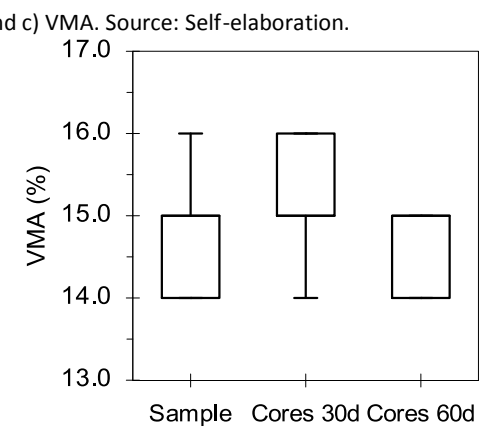

Figure 4a shows the density results for samples and cores respectively taken 30 and 60 days after road construction. The variance analysis (ANOVA, $p<0.05$ ) revealed that the density means are not significantly different with probability of 0.18 , indicating that there is no evidence of a significant change in densities with aging. The specification limits for VA are within the range of 3 and $5 \%$ (Table 3). The air voids values determined for samples and cores are shown in Figure $4 \mathrm{~b}$. As for density, the differences between means are not significant, with a probability of 0.19 . The minimum value determined for samples is $3.00 \%$ while for cores is $3.05 \%$, values that are within the lower limit specifications. The maximum value for samples and cores at 60 days is $4.95 \%$. However, for cores taken after 30 days two samples exceed the required limit of $5.00 \%$, with values of 5.84 and $5.97 \%$, but less than $6.00 \%$, which is the maximum theoretical limit to avoid premature asphalt hardening and disintegration. The results for VMA are depicted in Figure 4c. In all cases is the minimum value 14 and the maximum 16. The specification indicates that minimum VMA must be 14 , so this criterion is fulfilled in all cases. The VMA means, as in previous cases, do not significantly differ $(p=0.226,>0.05)$, indicating that this value can also be verified after mixture placing. Since VFA is related to VA and VMA and for neither of those parameters significant differences were observed in samples and cores, it is logic that the VFA results do not differ significantly either, obtaining a value of $p=0.20(>0.05)$ in the ANOVA test. 
Marshall stability and flow results for samples and cores are presented in Figure 5. For stability is a significant variation of the means observed $(p=0.0007,<0.05)$. From Figure $5 a$ it is observed that the stability increases from the day of mix placing (samples) up to 30 days and even more thereafter. According to the regulations for heavy traffic is a minimum Marshall stability of 1800 pounds required, a value exceeded in all tests. The increase of stability could be attributed to additional compaction after laying, and to asphalt stiffening that increases the overall stability. It is important to mention that all stability values were corrected according to specimen thickness and specifications (ASTM D6927).

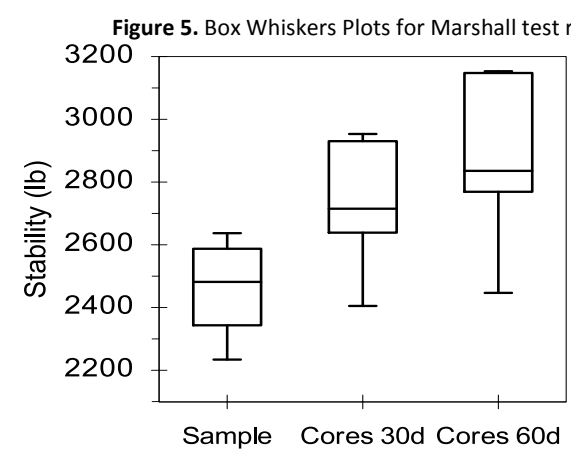

a)

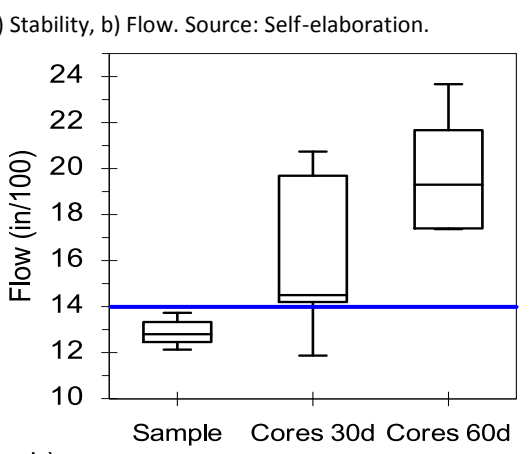

b)

The flow parameter ranges within 8 to 14 in/100 (Table 3). The means, as shown in Figure 5b, are significant different $(p=3.76 e-6,<0.05)$. In the case of samples varies the flow parameter between 12.13 and 13.73. After 30 days is the minimum observed value for cores 11.87 and the maximum 20.74, exceeding the specification of 14 . The average flow value of all cores 30 days after placement is 15.85 . For cores taken 60 days after construction increases the value of flow even more, varying between 17.37 and 23.67, with an average value of $19.45 \mathrm{in} / 100$; all measured values after 60 days exceed 14. High flow values are usually related to plastic mixtures subject to permanent deformations. However, it is noticed that standard flow values refer to tests carried out on samples at the moment of mix placing. In general, the samples fulfilled what was required but when testing cores, flow values exceed the maximum. It is worth noting that further studies are necessary in order to investigate the reasons behind the variation in stability and flow over time.

\section{Conclusions and Recommendations}

The study presents the analysis and comparison of hot mix asphalt parameters, respectively derived during the construction process and the same parameters measured on extracted cores 30 and 60 days after construction. Excluding flow values, parameters such as mixture density, aggregate gradation, asphalt bitumen content, VA, VMA, and Marshall stability, measured on cores could be retro used to define the quality of HMA after placement of the bitumen mixture. The mixture field density is one of the most significant property to determine pavement performance, hence, an adequate density control in the field must be performed.

Based on the analysis of the cores taken 30 and 60 days after construction, it is clear that aging of the hot mix asphalt does not significantly alter aggregate gradation, mixture field density, VA, VMA and VFA. However, Marshall flow obtained from cores must be considered as an informative parameter and should not be used to approve or reject the pavement works.

Additionally, it is recommended that QC should not only be based on Marshall Test results; results of rutting and cracking tests might also provide useful information. In this respect, it is important for public organizations to update its test procedures and specifications to guarantee the best performance of HMA works. As recommendation, the applied construction techniques should be considered as well in the QC process. Finally, research using other types of materials and in different regions will be necessary for the generalization of the results obtained in this study.

\section{Acknowledgments}

The authors wish to thank Hidalgo e Hidalgo S.A. for the provision of the materials and for facilitating its dependencies for the preparation and execution of tests. Thanks, are also due to the project supervision company Consorcio UCuenca EP and Consulproy Cia. Ltda., in particular for the support and logistics provided throughout the research project. Finally, the authors would like to thank the anonymous reviewers for their comments and useful suggestions that helped to improve this manuscript. 
Airey, G. (2003). State of the art report on ageing test methods for bituminous pavement materials. International Journal of Pavement Engineering, 4(3), 165-176, doi:10.1080/1029843042000198568.

ASTM D6927-15 (2015). Standard test method for Marshall stability and flow of asphalt mixtures. ASTM International, West Conshohocken, PA, US.

Decker, D. S. (2017). Specifying and measuring asphalt pavement density to ensure pavement performance. Technical report 856 , National Cooperative Highway Research Program (NCHRP), doi:10.17226/24870.

Fernández Gómez, W., Rondón Quintana, H., \& Reyes Lizcano, F. (2013). A review of asphalt and asphalt mixture aging. Ingeniería e Investigación, 33(1), 5-12.

Hu, X., Jiang, X., \& Pan, P. (2017). Effect of sample setting time on experimental evaluation of hot mix asphalt. Construction and Building Materials, 152(C), 375-385, doi:10.1016/j.conbuildmat.2017.07.012.

MTOP (2002). Ministerio de Transportes y Obras Públicas. Especificaciones Generales para la Construcción de Caminos y Puentes. MOP-001-F 2002, Ecuador.

Ogundipe, O. M. (2016). Marshall stability and flow of lime-modified asphalt concrete. Transport Research Arena, TRA2016. Transportation Research Procedia, 14(C), 685-693, doi:10.1016/j.trpro.2016.05.333.

Roberts, F., Kandhal, P., Brown, E. R., Lee, D., \& Kennedy, T. (1996). Hot Mix Asphalt Materials, Mixture Design and Construction. National Asphalt Pavement Association, Lanham, MD, second edition.

Rondón Quintana, H. \& Reyes Lizcano, F. (2012). Evaluación de los parámetros mecánicos de una mezcla asfáltica sometida a las condiciones ambientales de la ciudad de Bogotá D.C. Revista Ingeniería de Construcción, 27(1), 57-74, doi:10.4067/S0718-50732012000100004.

TRB (2000). Hot Mix Asphalt Paving Handbook. Transportation Research Board, U.S. Department of Transportation and U.S. Army Corps of Engineers, Washington DC, US.

TRB (2005). Glossary of Highway Quality Assurance Terms. Transportation Research Circular, No. E-C010. Transportation Research Board, National Research Council, Washington DC, US.

USDOT (2001). HMA Pavement Mix Type Selection Guide. Technical report IS 128, National Asphalt Pavement Association and Federal Highway Administration, Washington DC, US.

Valdés Vidal, G., Calabi-Floody, A., \& Sánchez-Alonso, E. (2015). Evaluation of the durability of asphalt mixtures depending on the physical properties of aggregates. Revista de la Construcción, 16(1), 92-103.

Walubita, L. F., Faruk, A. N., Zhang, J., Hu, X., \& Lee, S. I. (2016). The Hamburg rutting test effects of HMA sample sitting time and test temperature variation. Construction and Building Materials, 108(C), 22-28, doi:10.1016/j.conbuildmat.2016.01.031. 